ASIAN JOURNAL OF MANAGEMENT STUDIES

Journal homepage: https://www.sab.ac.lk/ajms/

Faculty of Management Studies Sabaragamuwa University of Sri Lanka

\title{
Strategic Outcomes of and Future Outlook for Data-based Disaster Management: A Case Study in Sri Lanka
}

\section{Rathnayake Mudiyanselage Wasantha Rathnayake}

Department of Tourism Management, Faculty of Management Studies, Sabaragamuwa University of Sri Lanka, Belihuloya, Sri Lanka

\section{ABSTRACT}

The preparation and implementation of Disaster Management Plans and the National Emergency Plans are enabled by data collection, data storing and data sharing. The required data can be specified as environment- and disaster-related data relevant to the Sendai Framework and Rio Conventions. A case study was carried out in the district of Badulla, which has recorded the highest number of disaster events in Sri Lanka, in order to explore the gaps in data and information management, with the ultimate objective of ensuring a disaster-minimised district. The study revealed that there are shortcomings in data collection, data storage and data sharing, which are important for fulfilling the requirements of four pillars of disaster management, i.e., mitigation-minimising the effects of disaster, preparedness-planning on how to respond, response-efforts to minimise hazards created by a disaster; and recovery-returning the community to normal.

Keywords: Data Management, Disaster Management Plans, Environment-related Data, Inter-agency Coordination, Rio Conventions, Sendai Framework

(C) Faculty of Management Studies Sabaragamuwa University of Sri Lanka

ARTICLE INFO Article history:

Received: 05 November 2020 Accepted: 02 January 2021

Published: 09 February 2021

E-mail Address:

warath1@gmail.com 


\section{INTRODUCTION}

Sri Lanka has experienced a variety of both natural and human-induced disasters that have had a disastrous impact on human wellbeing as well as the economic welfare of the country. The 2004 Tsunami is an extreme example of a devastating disaster from which Sri Lanka is yet to recover. Apart from the 2004 Tsunami, which could be taken as a rare and unique event, Sri Lanka is also impacted by other hazards that occur more or less on a yearly, if not, on a more frequent basis.

Disaster management efforts aim to reduce or avoid the potential losses from hazards, assure prompt and appropriate assistance to the victims of a disaster, and achieve a rapid and effective recovery. With modern challenges such as population increase, resource constraints, conflicts, and developmentrelated modifications to land use and landscape conditions, the potential for disaster has increased even more due to such human-induced disaster triggers.

The devastating Indian Ocean Tsunami of December 2004 was a watershed with regard to disaster management in Sri Lanka. The Sri Lanka Disaster Management Act No. 13 was enacted in 2005 and, under provisions of this Act, the National Council for Disaster Management and district-level Disaster Management Centers were established for the purpose of disaster management. The Act defines disaster as an actual or imminent occurrence of a natural or manmade event, which endangers, or threatens to endanger, the safety or health of any person or group of persons in Sri Lanka, or which destroys or damages, or threatens to destroy or damage, any property. In addition, riverbank erosion, toppling of trees, and human-animal conflicts are also experienced by Sri Lankans among what constitutes 'disaster' in Sri Lanka. Under the provisions of this Act, a National Disaster Management Plan and a National Emergency Operation Plan have to be prepared in order to ensure (i) preparedness for disasters and any other emergencies; (ii) risk prevention; and (iii) the prevention and mitigation of disasters. All these 'plan preparations' and 'implementations' are enabled by data collection, data storing, and data sharing. The required data can be specified as environmentand disaster-related data.

In order to achieve the Sustainable Development Goals (SDGs), it is important that any development project proposed by sector agencies includes measures to conserve environmental resources and reduce potential disaster 
risks. Development agencies must consider environmental data, particularly related to biodiversity, climate change, and land degradation, from the design phase of a project to its implementation. Enhancing development agency capacity to utilise environmental and disaster data in developing and evaluating project proposals is thus an essential component of this process.

During disasters, the need for data and information changes continuously. Scholars all over the world have emphasised the importance of the collection of various types of data, including those on topography, soil, vegetation, land usage, precipitation and water levels, and their analysis in disaster situations. Additionally, they have tried to identify the challenges and future research directions (Kohler \& Wachter, 2006; Hristidis et al., 2010; Goswami et al., 2018) in disaster management. A study by Wu and Cui (2018) have looked at how social media data and geo-location information can be applied in disaster early warning and damage assessment analysis.

Meanwhile, scholars like Akter and Wamba (2019) have proposed a big-data-driven approach to disaster response through sentiment analysis. Utilising advances in software, other researchers have developed models for disaster management systems, including floods, using data on disaster management (Qiu et al., 2017; Ragini et al., 2018; Akter \& Wamba, 2019).

On the other hand, Goswami et al. (2018) have reviewed the application of data mining and analytical techniques designed so far for prediction and detection of disasters and development of appropriate disaster management strategies based on the collected data from disasters. They have also highlighted the importance of maintaining a database for disaster management.

A typical disaster management cycle includes mitigation, preparedness, response, and recovery (Board on Natural Disasters National Research Council, 1999). They are all phases in disaster management that demand specific data and information.

According to Foster and Grossman (2003) and Saleem et al. (2008), the concept of a Disaster Management Dataspace should be established based on methodologies for disaster-related data acquisition, ingestion, organisation, and representation (Saleem et al., 2008). However, Foster and Grossman (2003) have pointed out that the mere availability of such data does not 
eliminate the challenge of designing and developing effective strategies for data acquisition, ingestion, and organisation. On the other hand, as scholars have shown, although a large quantity of disaster-related data is available, including response plans, records of previous incidents, simulation data, and data on social media web sites, current data management solutions offer few or no integration capabilities (Grolinger et al., 2013).

It is obvious that according to the official and unofficial records maintained by the government agencies in Sri Lanka, some development projects have failed and/or have resulted in disasters due to lack of data and data collection, data storing, and data sharing at different stages of the project cycle. However, these processes are important in the planning and monitoring phases of different development projects in Sri Lanka, the absence of which could result in disasters. The objectives of the present study are to explore the gaps in data and information management related to environment and disasters and to identify the root causes of the shortcomings in disaster management in the Badulla district in Sri Lanka.

\section{STUDY AREA}

Badulla District was selected as the study area, which is situated in 6059 '05'N and 81003'23'E, encompasses approximately about $2861 \mathrm{~km} 2$ area (Jayasinghe et al., 2017). The physical landscape of the district is complex with mountain ranges, divided plateaus and narrow valleys. Geologically, the district belongs to the rock formation of the highland series. The soil types in the district include Red Earth and Brown Loams, Red-Yellow Podsols and Reddish Brown Soils. Topographically, the Monaragala district is in a transitional zone ranging from areas falling within the central highlands to those located in the flat lowland. Three terrain types have been identified in the district, namely, highly mountainous, hilly-steep and rolling, and undulating and flat terrain. The average annual rainfall in the Badulla district varies from $900 \mathrm{~mm}$ to over $2,500 \mathrm{~mm}$. The district receives rainfall during four seasons, namely, the first inter-monsoon (March-April), the southwest monsoon (July-September), the second inter-monsoon (October-November) and the northeast monsoon (December-January). Partial drought occurs very often during the periods of February to July. 
The district of Badulla is located in the Uva Province. A prominent natural hazard in the district is landslides that occur during heavy rains. Their occurrence is the result of both natural and manmade causes. Among the natural causes are earth movements, rock falls, cracks, creek movement, localised earth slips and partial slides. Among manmade causes are activities such as large-scale sand-mining, gem-mining, quarrying of dolomite, etc., which have aggravated the frequency of disasters in a district already at high risk of natural disasters. Of the natural disasters, landslides have caused loss of lives, damages to infrastructure, disruption of social stability, adverse effects on education and health, economic failure, loss to farming, and environmental degradation and pollution. In addition to landslides, the other commonly reported disasters in the Badulla district are floods, manmade forest fires, drought, lightning, and the human-elephant conflict.

There are 15 Divisional Secretary Divisions in Badulla district, namely, Badulla, Bandarawela, Ella, Hali-Ela, Haputale, Kandaketiya, Lunugala, Mahiyanganaya, Meegahakivula, Passara, Rideemaliyadda, Soranathota, UvaParanagama and Welimada. Each division is administered by a Divisional Secretary, and is known as a D.S. Division (DSD) (Figure 1).

According to the available information on disasters, the main reasons for the disasters recorded in the Badulla district are topography and geology, climate, improper land use (constructions, agricultural practices, etc.), and deforestation. Accordingly, about $66.91 \%$ of the land area of the Badulla district is in danger, which is roughly $1914.29 \mathrm{~km} 2$ of the total land area of $2861 \mathrm{~km} 2$. Furthermore, about $2.77 \%$ of the land area has been identified as high risk (Figure 2). 


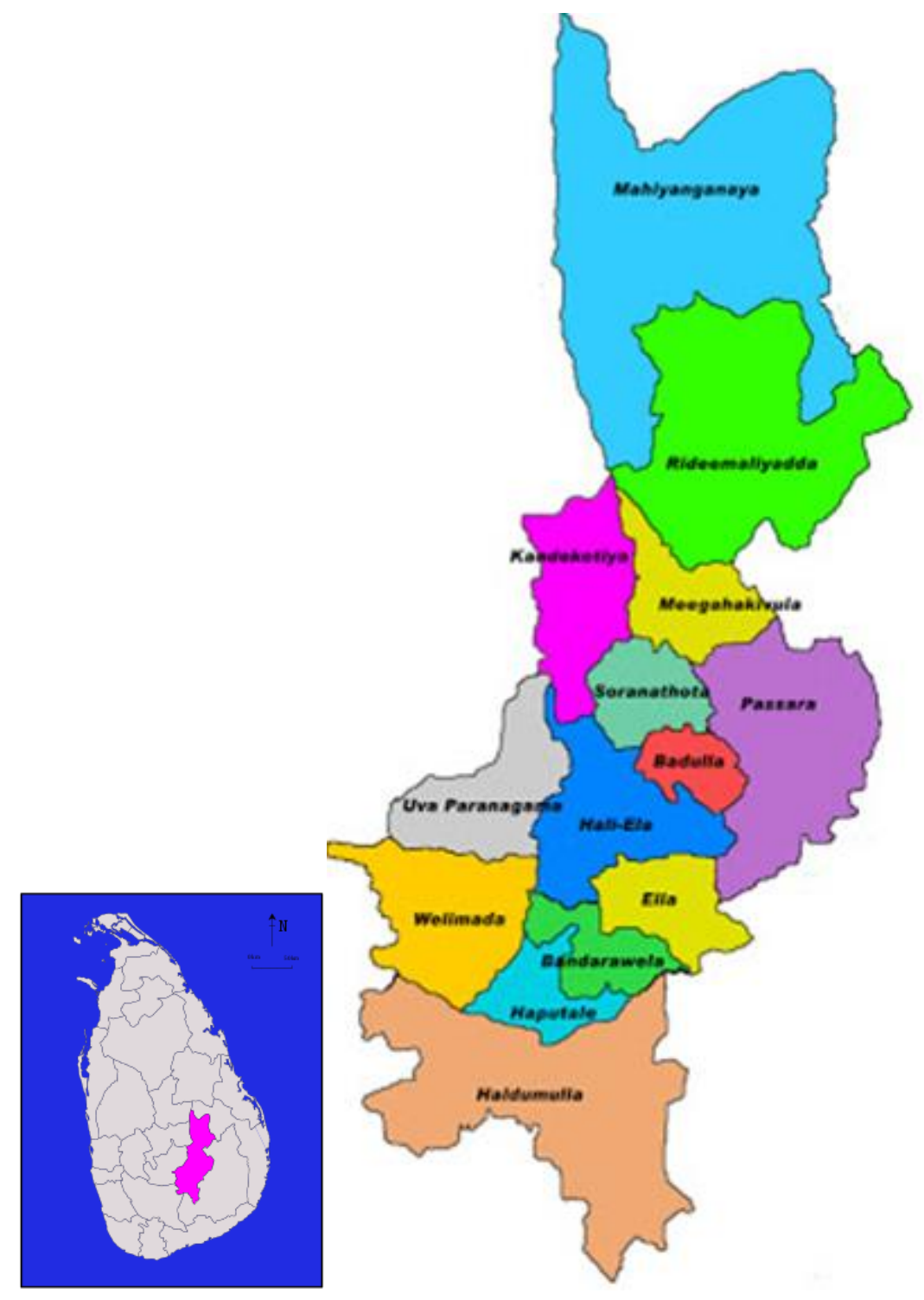

Figure 1: Divisional Secretariat Divisions in Badulla District, Sri Lanka 


\section{Badulla District in Risk Zones}

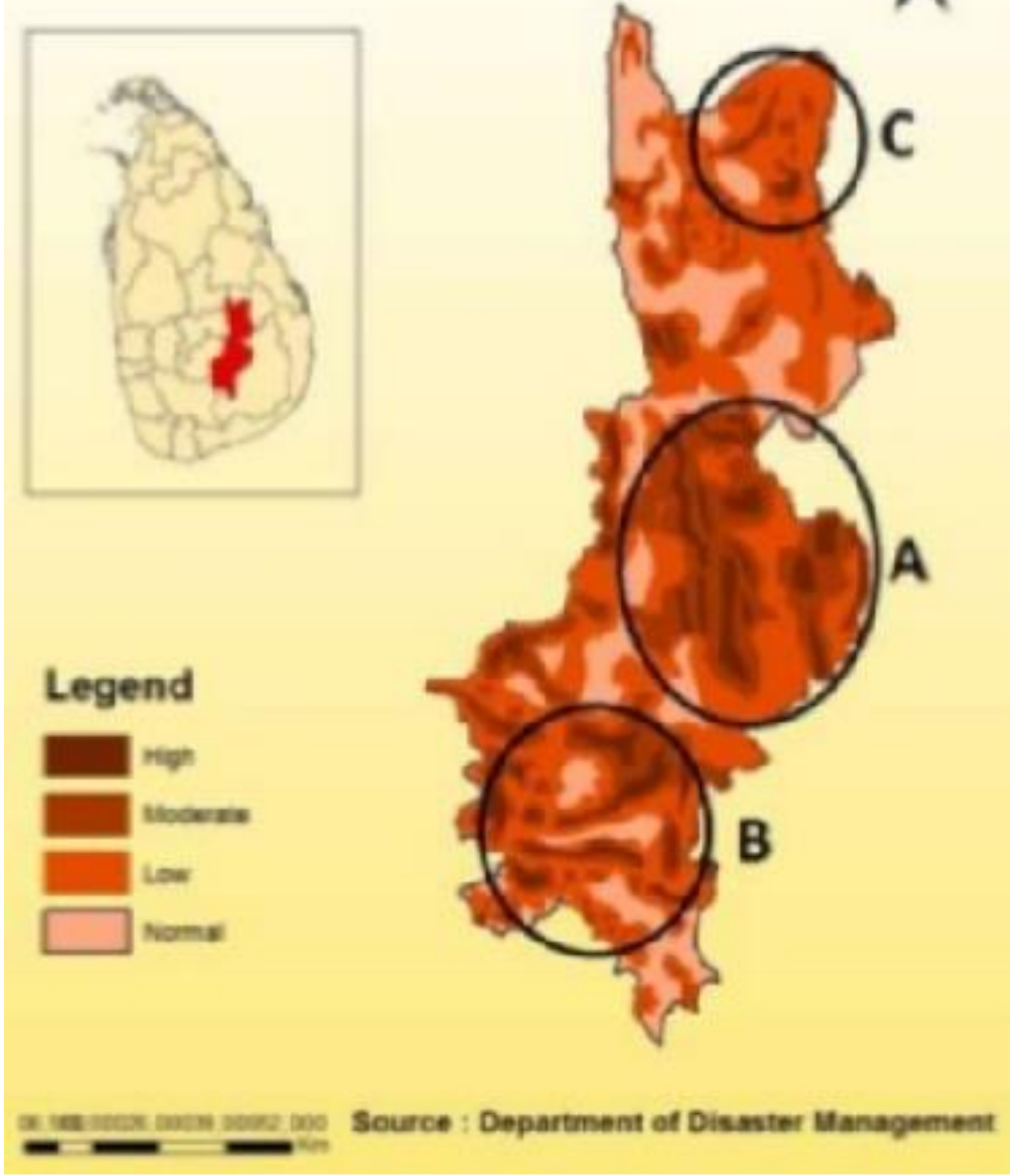

Figure 2: Land Slide Risk Zones in Badulla District 


\section{METHODOLOGY}

The study was undertaken in all Divisional Secretariats (DS) in the Badulla district. Data relevant to environment and disaster were mainly collected by referring to the existing literature on divisional-level resources, resource profiles, hazardous profiles and other environment- and disasterrelated data contained in documents. During the study period, at least two visits were made to each Divisional Secretariat and discussions were held with the relevant officers of the DS offices to collect data. The following key points were discussed at each DS office using a pretested data collection format: the role of the DS when there is a disaster; support from other government agencies when there is a disaster; issues when handling a disaster; availability of a resource profile; availability of a hazardous area profile; gaps/issues in the above systems; DS-level awareness sessions for officers involved in the collection and reporting of environmental and disaster data; and availability of a disaster management plan.

In addition, some of the techniques of Participatory Rural Appraisal (PRA)-i.e., group discussions, brainstorming sessions, and structural interviews-were used with the responsible officers or officers in charge of the following key stakeholder institutions in order to collect the relevant information on institutional level mandates, institutional level mechanisms, and practices applicable to the collection, storing and sharing of data related to environment and disaster. The key stakeholder agencies that participated in the PRA exercises are given in Table1.

The existing resource profiles and hazardous profiles were also studied to get an idea of how the agencies collect, store and share the existing data.

\section{RESULTS AND DISCUSSION}

\section{The Status of Data Collection, Data Storage and Data Sharing at Divisional Secretariat Level}

The type and magnitude of the disaster faced could vary from one DS to the next. While landslides are the main type of disaster faced by many DSs, flooding is the main issue in the Mahiyanganaya DS division and drought and human-elephant conflict, the main disasters in the Rideemaliyadda DS division. In contrast, the Soranathota DSD has not, to date, experienced any major disasters. All the DS divisions, except Bandarawela DS division, have 
resource profiles with specific information under broad categories such as geographic information, details of Grama Niladhari divisions (or GN division, which is a village cluster), and data on population and housing, agriculture, health, transport, communication, land use, details of government and civil societies, climate, forest and wildlife areas, water resources, and development projects in the area.

All the DS divisions, except Welimada DS division, have Hazardous Area Profiles but the scale of information available at different DS divisions varies with regard to the aspects and type of hazard, hazard-prone areas, level of risk, estimate of damage (cost), affected households, affected lands, maps of hazardous areas, management plans, contact details, resources, reasons for disasters, and identified solutions.

Some DS divisions already have disaster management and response plans in place. While the DS division of Haldummulla has a Disaster Recovery Preparedness and Response Plan, the DS divisions of Badulla and Mahiyanganaya have 5-year disaster management plans. Hali-Ela and Passara DS divisions have prepared Situational and Management Plans, quite similar to disaster management plans, for their DS divisions. Updated versions of these hazardous profiles are available for the years 2016/2017.

All DS divisions have collected and stored the data with regard to disasters as either manual systems or as soft copies (either PDF or Word document) and published them in the Sinhala language (one of the official languages of Sri Lanka). Some DSDs like the Badulla DSD maintain data in excel formats. But it was evident that they do not have proper systems to manage or share either data or databases.

Generally, most of the DSDs share data with other state institutions when a request is made barring a few like the Soranathota DS division. Some DS divisions assign a separate person to maintain the data when there is a disaster (for e.g., Lunugala, Kandeketiya, Rideemaliyadda, Passara, Soranathota and Uva-Paranagama DS divisions). But some DSDs do not have a dedicated member of staff to maintain the data relevant to disaster management. Instead, it is done by different categories of officers, among them, Development Officers, National Disaster Relief Centre Officers, Assistant Directors, Administrative GN officers, and Public Management Assistants. 
In some DS divisions, GND-wise disaster information reports are available (e.g., Haldumulla, Bandarawela and Uva-Paranagama DS divisions). In the Lunugala and Karandeniya DS divisions, where there was a database, the non-availability of computers and of internet facilities posed a problem with regard to its maintenance. Some DS divisions have highlighted the need for a mobile app to better respond to disaster as such an app would enable them to easily update data, for e.g., GPS locations, pictures, etc. of the disaster sites.

Some DS divisions highlighted the lack of updated data as an issue when handling a disaster, especially up-to-date maps and population data. They also highlighted the lack of data in other fields such as that of material resources, for e.g., the availability of vehicles, JCB machines, electricity, chain saws, and generators. They also felt that the lack of funds and fixed communication systems such as radio or satellite would constitute a major impediment in case of a disaster.

Delays in sharing data with DS divisions by several institutions is also a problem when handling disasters. For e.g., the Meegahakivula DS division reported the absence of relevant maps, reports of National Building Research Organisation (which is responsible for determining the landslide-prone sites in a particular area), and data issued by the National Disaster Relief Services Centre. Moreover, DS divisions did not find some of the data provided by other institutions reliable for the purpose of making decisions. An example would be the risk areas marked by NBRO when compared with areas actually experiencing disasters.

\section{The Status of Data Collection, Data Storage and Data Sharing at District Level}

The responsible officers from all the state institutions in Badulla district were interviewed for the purpose of identifying the status of data collection, data storage and data sharing, and formats used for data collection, storing and sharing. The collected data and information were then studied in detail and analysed, taking into consideration the data fields mentioned in the Rio Conventions and Sendai Framework in addition to each institution's mandate. The summary findings are given in Table 1 . 
Table 1: Findings of Availability of Data Relevant to Climate Change, Convention on Biological Diversity and Land Degradation, Desertification and Drought at State Institutions in Badulla District

$$
\begin{gathered}
\text { Availability of Data Relevant to Climate } \\
\text { Change, Convention on Biological Diversity } \\
\text { and Land Degradation, Desertification and } \\
\text { Drought }
\end{gathered}
$$

\section{Department of Census and Statistics}

Department of Census and Statistics collects, stores and shares the relevant data and information on Climate Change and the Convention on Biological Diversity. The data is maintained as excel files, web-based documents/reports and maps at Divisional Secretariat level and GN levels.

National Building and Research Organisation (NBRO)

NBRO has been collecting, storing and sharing data relevant to Climate Change (geographical data, rainfall data and landslide data) from 2011 to date. Under Land Degradation, Desertification and Drought (LDD\&D), maps and relevant documents on landslides are available from 2011 to date. The data and information is collected, stored and shared.

Forest Department
Data and information on land use change and
forestry emissions under climate change are
currently not available. There is an ongoing
national project to collect and store data in
these fields. By 2021, this project will be
completed. Under the Convention on
Biological Diversity, the data/information
required for the data fields are collected, stored
and shared. Data on forest fires, encroachments
and reforestation under the aspect of Land
Degradation, Desertification and Drought
(LDD\&D) are available. The data collected are
up to date, and maps have been prepared for
information sharing.

Survey Department

The Survey Department collects and stores data for the relevant extent of forest cover and land use under the Convention on Biological Diversity. The data are shared with other

\section{Remarks}

Available data are not sufficient to fulfill all the required data fields mentioned under Climate Change and Convention on Biological Diversity. Data are not available for the data fields mentioned under Land Degradation, Desertification and Drought (LDD\&D).

Relevant data are collected as per their mandate. Depending on the type of request, the collected data are shared either free of charge or on a fee-levying basis. There is no proper data-sharing mechanism with other state institutions.

There is no proper data sharing
mechanism, and data has to be obtained from the Head Office. Data are not available for all fields mentioned under Climate Change, Convention on Biological Diversity, Land Degradation, Desertification and Drought.

Some data are available relevant to the Convention on Biological Diversity. The maps, last updated in 2010, are in need of updating. 
organisations in the form of maps prepared by them. The maps were updated in 2010.

Urban Development Authority (UDA)

Data relating to blocking out land for townships is available in both soft and hard formats (e.g., reports, maps, plans) for Land Degradation, Desertification and Drought (LDD\&D) and are collected, stored and shared by the UDA.

Department of Agriculture

Data on trends in crop productivity under Climate Change are collected, stored and shared by the Department of Agriculture. The office has maintained data for more than six years. The required and relevant data under the agricultural ecosystem are only available for the Convention on Biological Diversity. Under the aspect of Land Degradation, Desertification and Drought (LDD\&D), data on land suitability and soil conservation are collected, stored and shared by the Department of Agriculture.

Agrarian Services Department

The Agrarian Services Department stores data on trends in crop productivity relevant to Climate Change. The available data were collected six years ago. Under the Convention on Biological Diversity, the relevant data on agricultural ecosystems are collected, stored and shared by the Department of Agrarian Services, although the data had been collected more than five years ago. Data on soil conservation, fertility restoration, soil quality and productivity are available for the aspect of Land Degradation, Desertification and Drought (LDD\&D).

Department of Irrigation

Data relevant to trends in crop productivity under the data field of Climate Change are collected and stored by the Irrigation Department. These data have been collected and stored for more than ten years and are shared on request. With regard to data required for the Convention on Biological Diversity, some data on the fields of agricultural ecosystems have been collected and stored, but
Some data are available only for the data fields mentioned under Land Degradation, Desertification and Drought (LDD\&D).

No proper data-sharing mechanism could be found. Data are not available for all the fields mentioned under Climate Change, Convention on Biological Diversity, Land Degradation, Desertification and Drought.

Data are not available for all the fields mentioned under Climate Change, Convention on Biological Diversity, Land Degradation, Desertification and Drought.

Only some data are collected and stored for the data fields of Climate Change, Convention on Biological Diversity, Land Degradation, Desertification and Drought. 
these data had been collected many years ago. Data are shared on request with other agencies. Under the aspect of Land Degradation, Desertification and Drought (LDD\&D), data are collected and stored on soil quality, soil conservation, drainage management, spatial distribution of paddy lands, status of soil quality, productivity, salinity and other abiotic problems, soil erosion, nutrient build-up, landslides, pollution of water bodies, streams, stream reservations, watersheds/catchments, reservoir distribution and water levels. The collection of data commenced about three years ago, and the data are shared with other agencies on request.

National Disaster Relief Services Centre (NDRSC)

NDRSC does not collect, store and share relevant data on Weather and Climate, the Convention on Biological Diversity, and Land Degradation, Desertification and Drought (LDD\&D).

\begin{tabular}{l} 
Road Development Authority (RDA) \\
Data on locations of construction with regard \\
to land degradation have been collected, stored \\
and shared by the RDA. \\
\hline Provincial Road Development Authority \\
(PRDA)
\end{tabular}

Data on locations of construction with regard to land degradation have been collected, stored and shared by PRDA. The data have been collected for more than five years.
Sufficient data are not collected, stored and shared in the fields mentioned under Climate Change, Convention of Biological Diversity, Land Degradation, Desertification and Drought (LDD\&D).

Data have been collected, stored and shared under land degradation relevant to road development.

Data have been collected, stored and shared under land degradation relevant to road development.

\section{Department of Land Use Policy Planning (LUPPD)}

This department has not been collecting, storing and sharing data and information relevant to Climate Change, Convention on Biological Diversity, and Land Degradation, Desertification and Drought (LDD\&D).

$\begin{aligned} & \text { Geological Surveys and Mines Bureau } \\ & \text { (GSMB) }\end{aligned}$
$\begin{aligned} & \text { Some data have been collected by GSMB } \\ & \text { relevant to the data fields of Climate } \\ & \text { GSMB does not collect and store relevant }\end{aligned}$
data/information under Climate Change and aspect of Liological Diversity under the
the Convention on Biological Diversity. Under Desertification and Drought. The data are
the aspect of Land Degradation,

They collect, store and share data relevant to their mandate if and when necessary. However, a proper data collecting and sharing mechanism is not available.

Faculty of Management Studies, Sabaragamuwa University of Sri Lanka 
Desertification and Drought (LDD\&D), relevant data on sand mining and metal quarries are collected and stored by GSMB. But the available data had been collected over 5 years ago.

Disaster Management Centre (DMC) - Badulla

Weather and Climate Data are collected, stored and shared by DOM. Data on precipitation, temperature, pressure, and humidity are collected daily and calculated as monthly \& annual figures. Anomalies (for e.g., dew point, vapor pressure, etc.) are collected daily and calculated monthly and annually. All data of the Department are sent to the Head Office. All data storing and analysis are undertaken by the Head Office. The database in Colombo is made available for use when requests are made by other government agencies in Badulla. Climate modeling is under preparation by the DMC (Data are available in both excel format and MS word formats).

Department of Meteorology The department collects, stores and shares for the data fields of droughts and floods under Climate Change. Data collection has been in operation for more than five years.

Data on forest fires have been collected, stored and shared under the data field of Land Degradation, Desertification and Drought (LDD\&D).

National Water Supply and Drainage Board
(NWSDB)

Data on the quality of surface water flows are collected and stored in databases under the aspect of Land Degradation, Desertification and Drought (LDD\&D).

Municipal Council-Badulla
Data on methane $\left(\mathrm{CH}_{4}\right)$ emissions from
industrial treatment in plants and domestic and
commercial sites have been collected, stored
and shared by MC.
Data on solid waste dumping sites in the
Badulla Municipal Council area have been
collected and stored under the aspect of Land
Degradation, Desertification and Drought
(LDD\&D). in need of updating they had been collected sometimes ago.

Data are only available for the fields mentioned under Climate Change.

The Department mainly collects and stores weather and climate data. In addition, disaster-impact data are also collected and stored.

Data are not collected for the data fields mentioned under Climate Change, Convention on Biological Diversity and Land Degradation, Desertification and Drought (LDD\&D).

Some data have been collected, stored and shared under Climate Change and Land Degradation, Desertification and Drought (LDD\&D). 


\section{Key Findings of the Study related to Disaster Preparedness}

The case study finds that there are a lot of gaps with regard to disaster preparedness in the Badulla district of the Uva Province. Among the gaps identified are the following: (i) Each institution collects, stores and shares data/information relevant to their mandate and functions; (ii) Data are collected by each institution and stored in excel sheets, data bases or reports; (iii) There was no proper data sharing mechanism in many institutions; (iv) Most of the data is not collected by institutions according to the data fields mentioned under Climate Change, Convention on Biological Diversity and Land Degradation, Desertification and Drought (LDD\&D); (v) Most of the data is shared by institutions only on request by other institutions, with some institutions only providing data with approval from their respective Head Office; (vi) Data availability is not at a satisfactory level for required data fields mentioned under Climate Change, Convention on Biological Diversity and Land Degradation, Desertification and Drought (LDD\&D); (vii) There is no district-level central mechanism for data storage located at the District Secretariat or any of the Divisional Secretariats; (viii) The relevant institutions are not familiar with the Sendai Framework for Disaster Risk Reduction 20152030 outlines and the Rio Conventions that the Government of Sri Lanka is signatory to such as the Convention on Biological Diversity (CBD), the United Nations Framework Convention on Climate Change (UNFCCC), and the United Nations Convention to Combat Desertification; and (ix) Each individual institution collects, stores and shares data in different formats, for example, excel sheets, reports, questionnaires, maps, etc.

\section{Key Problems, Issues and Challenges for Disaster Management}

As shown by Smith and Hayne (1997), the process of information sharing and coordination is further impeded by the pressure of time and event uncertainty (Argote, 1982), which lead to unpredictability in information needs and flows (Longstaff, 2005).

In disaster management, the organisation and management of resources and responsibilities for dealing with all humanitarian aspects of emergencies, in particular, preparedness, response and recovery, to lessen the impact of disasters are required. In our study, the key problems, issues and challenges of the climate and disaster management sector were clearly identified by conducting discussions, interviews, focus group discussions and 
brainstorming sessions with key stakeholders by applying the techniques of participatory rural appraisal (PRA). Since it is obvious that disasters cannot be permanently eliminated, what is needed is the effective management of data to minimise impacts.

The study identifies and classifies the shortcomings with regard to disaster management in the District under four main aspects, namely, (i) Disaster risk reduction, (ii) Preparedness, (iii) Emergency operations, and (iv) Response and relief, recovery, resettlement, and rehabilitation. This shows that shortcomings in disaster risk reduction, preparedness for disasters, response to disasters, and recovery are identified as key problems in disaster management. The root causes of the problems relating to disaster management identified by the study in the Badulla district are lack of funds, constitutional and legal issues, lack of inter-agency coordination, and lack of sensitivity and awareness relating to disasters.

The effect of these root causes is evident in data collection, data storing, data sharing, limited decisions-making powers and procedural delays. Hence, while disaster is managed ultimately up to a certain level, it is far from satisfactory. Since the ultimate goal of the proposed disaster management plan is to strengthen the disaster management mechanism of the Badulla District, its objectives should be the following: minimising the disaster risk in the district; strengthening the preparedness for disaster management; strengthening the mechanism of emergency operations and response vis-à-vis disaster management; and strengthening the mechanism of relief, recovery, resettlement and rehabilitation.

Data collection, data storing and data sharing are the main outcomes envisaged by achieving the objectives mentioned above. Establishing interagency coordination, providing infrastructure facilities and training for staff, minimising carelessness of staff, minimising procedural delays, and providing duty lists and responsibilities are the other areas to be improved in disaster management. The ultimate goals of disaster management are reduction or avoidance of losses from hazards; assurance of prompt assistance to victims; and achievement of rapid and effective recovery.

It is a fact that in disaster management, despite the recent emergence of a large number of technological innovations, these technologies have often been developed in isolation of other developments and have not been 
integrated into the daily routine operations, which might thus prevent their effective use during an emergency. Many cultural, organisational, jurisdictional and legal barriers also impede or prevent necessary and proper coordination among relevant public and private organisations during unforeseen eventualities. However, traditional modes of coordination alone are inadequate for volatile and dynamic situations (Faraj \& Xiao, 2006). Information needs and appropriate coordination mechanisms relating to the needs of the people affected may also vary with changes in the disaster situation. There is a need, therefore, to develop flexible coordination mechanisms that could easily be customised for the specific situation and, thereby, provide better support for improvised responses where it is deemed necessary (Mendonca, 2007; Chen et al., 2008).

\section{CONCLUSION}

The findings of the study underscore the importance of a directive by the government to all relevant state institutions in Badulla to identify the existing district-level environmental and disaster-related data and to facilitate the planning divisions in the District Secretariats to design the conceptual framework for a district-level database on environmental and disaster data. Although inter-agency coordination has attracted a great deal of attention in the recent past, there are still several issues that require more research. For example, coordination of commitments based on relationships has received little attention within the field (Winograd \& Flores, 1987). In their study, Winograd and Flores (1987) found that most human coordination occurs in a basic cycle consisting of requesting, making and fulfilling commitments between people than at a more advanced and systematic level.

According to Faraj and Xiao (2006), the Coordination Theory is often claimed by scholars to be at the centre of organisation theory. The limited capacity and resources, the problems caused by the division of tasks and labour, and the corresponding mechanisms needed to overcome the problems form the core of organisational design (Galbraith, 1977). Although coordination has attracted a great deal of attention, there are several issues that require more research, among them, as pointed out by Winograd and Flores (1987), the coordination of commitments based on relationships. 
The identified thrust areas and result areas are given in Table 2. The future outlook is mostly related to the Sustainable Development Goals mentioned in the Rio Declaration and other drafted Rio Conventions and the Sendai Framework. The sustainable development goals cover social and economic development issues including poverty, hunger, health, education, global warming, gender equality, water, sanitation, energy, urbanisation, environment and social justice. The resulting outcomes are also related to sustainable development goals.

Table 2: The Thrust Areas and Key Result Areas

\begin{tabular}{|c|c|c|c|c|}
\hline Sector & Domain & Purpose & Thrust Areas & Key Result Areas \\
\hline \multirow[t]{5}{*}{$\begin{array}{l}\text { Disaster } \\
\text { management }\end{array}$} & $\begin{array}{l}\text { Quality } \\
\text { of life }\end{array}$ & $\begin{array}{l}\text { Safe lives } \\
\text { and } \\
\text { properties }\end{array}$ & $\begin{array}{l}\text { 1. Disaster risk } \\
\text { reduction } \\
\text { mechanism }\end{array}$ & $\begin{array}{l}\text { 1.1 Mechanism for data } \\
\text { collection, storing and } \\
\text { sharing }\end{array}$ \\
\hline & & & & $\begin{array}{l}\text { 1.2 Application of } \\
\text { evaluated risk potential } \\
\text { in development planning } \\
\text { 1.3 Community } \\
\text { understanding on land } \\
\text { use }\end{array}$ \\
\hline & & & $\begin{array}{l}\text { 2. Preparedness for } \\
\text { disasters }\end{array}$ & $\begin{array}{l}2.1 \text { Improved } \\
\text { preparedness mechanism } \\
\text { for minimising disaster } \\
\text { impacts }\end{array}$ \\
\hline & & & $\begin{array}{l}\text { 3. Improved } \\
\text { response for } \\
\text { disasters }\end{array}$ & $\begin{array}{l}\text { 3.1 Improved } \\
\text { mechanism for disaster } \\
\text { relief and response }\end{array}$ \\
\hline & & & $\begin{array}{l}\text { 4. Improved disaster } \\
\text { recovery, } \\
\text { resettlement and } \\
\text { rehabilitation }\end{array}$ & $\begin{array}{l}4.1 \text { Improved } \\
\text { mechanism for speedy } \\
\text { recovery, resettlement } \\
\text { and rehabilitation }\end{array}$ \\
\hline
\end{tabular}

Source: Stakeholder Workshop 2018

Based on the results of the PRA exercise as well as discussions with relevant officials, the following policy directions are proposed as recommendations to achieve the vision and mission of disaster management in the Badulla district.

(i). A policy decision should be taken to collect, store and share data by relevant agencies pertaining to the Sendai Framework for Disaster Risk Reduction 2015-2030 outlines, Convention on Biological Diversity (CBD), the United Nations Framework Convention on Climate Change (UNFCCC) and 
the United Nations Convention to Combat Desertification. This can be done through MOUs and Circulars which are part of the project;

(ii). Disaster management should be done according to the Sendai Framework for Disaster Risk Reduction 2015-2030. Data collection, data storage and data sharing are important for fulfilling the requirements of the four pillars of disaster management, i.e. mitigation-minimising the effects of disaster; preparedness-planning on how to respond; response-efforts to minimise hazards created by a disaster; and recovery- rehabilitating the community to pre-disaster levels. For this, a central database has to be established at the District Secretariat level to store and share the data/information among the relevant agencies;

(iii). Monthly/quarterly planning committee meetings should be held at the District Secretariat in order to discuss development projects and to make decisions based on the environment and disaster data collected;

(iv). Future development activities should be planned and information about them disseminated among all stakeholders within a specific time period (i.e., a year) in order to obtain their inputs as well as relevant data into the database for the purpose of decision-making on the development projects being implemented;

(v). A risk planning and management framework should be introduced to prepare for the possible failure of future projects;

(vi). Opportunities should be provided to the community to participate in decision-making in order to prevent disasters during future development projects. It is important to make local residents full and equal partners in development planning and decision making, particularly members of disadvantaged groups who tend to bear the brunt of the adverse outcomes of such projects;

(vii). A hazard assessment and vulnerability analysis, especially hazard proneness, should be included, at the appraisal stage, in all social and environmental risk assessments of development projects;

(viii). Frequent monitoring of and updating information on disaster-prone areas should be undertaken within the district based on small-scale/mediumscale/large-scale disasters with the participation of the GN and DS; 
(ix). Both infrastructure and budgets should be provided to support environmental management and risk reduction for the purpose of minimising the frequency, if not occurrence, of disasters.

Although these are the recommendations proposed, as Thompson (1967) has shown, disaster management is underpinned ultimately by reciprocity, mutual trust, and willingness to share information among organisations. As emphasised by him, these types of interactions should occur not only at the top tiers of the organisations but at the lower levels as well.

\section{REFERENCES}

Argote, L. (1982). Input uncertainty and organisational coordination in hospital emergency units. Administrative Science Quarterly, 27(3), 420434. doi:10.2307/2392320.

Akter, S., \& Wamba, S. F. (2019). Big data and disaster management: a systematic review and agenda for future research. Annals of Operations Research, 283, 939-959.

Board on Natural Disasters National Research Council. (1999). Mitigation emerges as a major strategy for reducing losses caused by natural disasters. $\quad$ Science, $284(5422), \quad$ 1943-1947. doi:10.1126/science.284.5422.1943

Chen, R., Sharman, R., Rao, R., \& Upadhyaya, S. (2008). Coordination in emergency response management. Communications of the ACM, 51(5), 66-73. doi:10.1145/1342327.1342340

Faraj, S., \& Xiao, Y. (2006). Coordination in fast-response organisations. Management Science, 52(8), 1155-1169. doi:10.1287/ mnsc.1060.0526

Foster, I., \& Grossman, R. L. (2003). Data integration in a bandwidth-rich world. Communications of the ACM, 46(11), 50-57.

Galbraith, J. R. (1977). Organisation Design. Reading, MA: Addison Wesley.

Goswami, S., Chakraborty, S., Ghosh, S., Chakrabarti, A. \& Chakraborty, B. (2018). A review on application of data mining techniques to combat natural disaster. Ain Shams Engineering Journal, 9(3), 365-378. doi: https://doi.org/10.1016/j.asej.2016.01.012 
Grolinger, K., Capretz, M. A.M., Mezghani, E., \& Exposito, E. (2013). Knowledge as a Service Framework for Disaster Management. Workshop on Enabling Technologies: Infrastructure for Collaborative Enterprises, Hammemet, pp. 313-318., doi: 10.1109/WETICE.2013.48

Hristidis, V., Chen, S. C., Li, T., Luis, S., \& Deng, Y. (2010). Survey of data management and analysis in disaster situations. Journal of Systems and Software, 83(10), 1701-1714. https://doi.org/10.1016/j.jss.2010.04.065

Jayasinghe, G. J. M. S. R., Wijekoon, P., \& Gunatilake, J. (2017). Landslide susceptibility assessment using statistical models: A case study in Badulla disdrict, Sri Lanka. Ceylon Journal of Science, 46(4), 27-41. DOI: http://doi.org/10.4038/cjs.v46i4.7466

Kohler, P., \& Wachter, J. (2006). Towards an Open Information Infrastructure for Disaster Research and Management: Data Management and Information Systems Inside DFNK. Natural Hazards, 38, 141-157.

Longstaff, P. H. (2005). Security, resilience, and communication in unpredictable environments such as terrorism, natural disasters, and complex technology. http://pirp. harvard.edu/pubs_pdf/longsta/longstap05-3.pdf

Mendonca, D. (2007). Decision support for improvisation in response to extreme events: learning from the response to the 2001 World Trade Center attack. Decision Support Systems, 43(3), 952-967. doi:10.1016/j.dss.2005.05.025

Qiu, L., Du, Z., Zhu, Q., \& Fan, Y. (2017). An integrated flood management system based on linking environmental models and disaster-related data. Environmental Modelling \& Software, 91, 111-126. https://doi.org/10.1016/j.envsoft.2017.01.025

Ragini, J. R., Anand, P. M. R., \& Bhaskar, V. (2018). Big data analytics for disaster response and recovery through sentiment analysis. International Journal of Information Management, 42(October), 13-24. https://doi.org/10.1016/j.ijinfomgt.2018.05.004 
Saleem, K., Luis, S., Deng, Y., Chen, S.-C., Hristidis, V., \& Li, T. (2008). Towards a business continuity information network for rapid disaster recovery. In S. A. Chun, M. Janssen, \& J. R. Gil-Garcia (Eds.), Proceedings of the 2008 International Conference on Digital Government Research ACM International Conference Proceeding Series (pp. 107116).

Smith, C., \& Hayne, S. (1997). Decision making under time pressure. Management Communication Quarterly, 11(1), 97-126. doi:10.1177/0893318997111005

Thompson, J. D. (1967). Organisations in action. New York: McGraw-Hill.

Winograd, T., \& Flores, F. (1987). Understanding computers and cognition. A new foundation for design. Massachusetts: Addison Wesley.

Wu, D., \& Cui, Y. (2018). Disaster early warning and damage assessment analysis using social media data and geo-location information. Decision Support Systems, 111(July), 48-59. https://doi.org/10.1016/j.dss.2018.04.005 